\title{
Effect of high-fat diet on the pharmacokinetics and safety of flumatinib in healthy Chinese subjects
}

\author{
Yun Kuang ${ }^{1} \cdot$ Hui-ling Song ${ }^{1} \cdot$ Guo-ping Yang ${ }^{1,2,3}$ (D) $\cdot$ Qi Pei $^{4} \cdot$ Xiao-yan Yang ${ }^{1} \cdot$ Ling Ye $^{1} \cdot$ Shuang Yang ${ }^{1}$. \\ Shu-ting $\mathrm{Wu}^{1}$. Can Guo ${ }^{1}$. Qing-nan $\mathrm{He}^{5,6}$. Jie Huang ${ }^{1}$ (i)
}

Received: 13 November 2018 / Accepted: 19 July 2020 / Published online: 5 August 2020

(c) The Author(s) 2020

\begin{abstract}
Purpose To evaluate the effect of a high-fat diet on the pharmacokinetics and safety of flumatinib mesylate tablets in healthy Chinese subjects.

Methods This study was a randomized, open-label, single-dose, two-period crossover trial in which subjects were randomly assigned to take $400 \mathrm{mg}$ of flumatinib mesylate after a high-fat diet or a fasted state. After a 14-day washout period, the two groups were administered flumatinib mesylate under opposite conditions. Blood samples were collected at baseline 0 and 0.5 , $1,1.5,2,2.5,3,4,5,6,8,10,12,24,48,72$, and $96 \mathrm{~h}$, respectively. Plasma concentrations of flumatinib and its metabolites (M1 and M3) were analyzed using liquid chromatography-mass spectrometry. Pharmacokinetic parameters were calculated using the non-compartmental module of the Phoenix WinNonlin Version 7.0 software. BE module of WinNonLin was used for statistical analysis of $\mathrm{AUC}_{0-\mathrm{t}}, \mathrm{AUC}_{0-\infty}$ and $C_{\max }$ in plasma.

Results Twelve healthy subjects, half male and half female, were enrolled. One subject withdrew due to a treatment-emergent adverse event. Eleven subjects were administered drugs on fasting and 12 were administered drugs after a high-fat diet. On high-fat diet/fasting, the least square geometric mean (LSGM) ratios of flumatinib, M1, M3, and their 90\% confidence interval (CI) were as follows: for flumatinib, $\mathrm{C}_{\max }, \mathrm{AUC}_{0-\mathrm{t}}$ and $\mathrm{AUC}_{0-\infty}$ were 281.65\% (225.80-351.31\%), 167.43\% (143.92194.79\%), and 166.87\% (143.47-194.09\%); for $\mathrm{M} 1, C_{\max }, \mathrm{AUC}_{0-\mathrm{t}}$, and $\mathrm{AUC}_{0-\infty}$ were 188.59\% (145.29-244.79), 163.94\% (149.11-180.24\%), and 164.48\% (150.36-179.94\%); for $\mathrm{M} 3, C_{\max }, \mathrm{AUC}_{0-\mathrm{t}}$, and $\mathrm{AUC}_{0-\infty}$ were $63.47 \%(54.02-74.57 \%)$, $85.23 \%$ (74.72-97.22\%), and 96.73\% (86.63-108.02\%).
\end{abstract}

Conclusion Among the subjects, oral administration of $400 \mathrm{mg}$ of flumatinib was safe and well tolerated. High-fat diet significantly increases the exposure to flumatinib, therefore, fasting may be recommended.

Clinical trial registration The study was registered at chictr.org Identifier: ChiCTR-IIR-17013179.

Keywords Pharmacokinetics $\cdot$ Flumatinib $\cdot$ High-fat diet $\cdot$ Healthy subject

Yun Kuang and Hui-ling Song contributed equally to this work.

Qing-nan He

heqn2629@163.com

$\triangle$ Jie Huang

cellahuang1988@163.com

1 Center of Clinical Pharmacology, The Third Xiangya Hospital, Central South University, Changsha, Hunan, China

2 Research Center for Drug Clinical Evaluation, Central South University, Changsha, Hunan, China

\section{Background}

Chronic myelogenous leukemia (CML) also called chronic granulocytic leukemia, is a slowly progressing blood and bone marrow disease that usually occurs during or after middle age,

3 XiangYa School of Pharmaceutical Sciences, Central South University, Changsha, Hunan, China

4 Department of Pharmacy, The Third Xiangya Hospital, Central South University, Changsha, Hunan, China

5 Research Center for Drug Clinical Evaluation of Central, Central South University, Changsha, Hunan, China

6 Department of Pediatrics, The Third Xiangya Hospital, Central South University, Changsha, Hunan, China 
and rarely occurs in childhood [1]. A reciprocal chromosome translocation (9 and 22), called the Philadelphia chromosome, causes a constitutive activation of the BCR-ABL tyrosine kinase, leading to CML [2-5]. Current strategies for CML treatment involve the use of tyrosine kinase inhibitors, which can inhibit the BCR-ABL phosphorylation, thereby preventing the proliferation of cancer cells and activating subsequent apoptosis [2, 6-9]. Currently, resistance to the first-line drug imatinib has led to the development of other novel tyrosine kinase inhibitors [10].

Previous pharmacokinetic (PK) data of flumatinib showed that it was safe and well-tolerated, and $\mathrm{Cmax}$ and $\mathrm{AUC}_{0-\mathrm{t}}$ were linearly related to doses in the range of 200-1000 $\mathrm{mg}$ [11]. Preclinical pharmacokinetic studies showed that, in rats and beagles, the maximum blood concentration could be reached in about $5 \mathrm{~h}$ after oral administration of the drug. Furthermore, flumatinib mesylate was widely distributed in tissues, with tissue drug concentration higher than that in plasma concentration. The parent drug flumatinib was present in plasma, urine, and feces. The primary metabolites in plasma were $\mathrm{N}$-desmethyl flumatinib (M1), which was approximately $10 \%$ of that of the parent drug in plasma and has been shown to have similar pharmacological properties as the parent drug. The amide hydrolysis product (M3), which was inactive but approximately $30 \%$ of that of the parent drug in plasma [12]. Therefore, plasma concentrations of flumatinib, M1, and M3 were necessary to evaluate their circulating levels in humans.

Several studies have shown that gastrointestinal reactions, including abdominal pain, diarrhea, bloating, are the most common adverse reactions to tyrosine kinase inhibitors [13-16]. Therefore, tyrosine kinase inhibitors are often recommended to be administrated with food. However, food may affect gastric $\mathrm{pH}$, emptying, and movement in the stomach, subsequently affecting drug absorption. In addition, since flumatinib is a lipophilic drug, and thus a high-fat diet may increase its solubility and (relative) bioavailability [17, 18]. Results from the Phase Ia clinical trials showed that the flumatinib absorption increased when administrated orally with food. However, as there are many influencing factors in patients with Phase Ia, it is important to evaluate the effect of food on the pharmacokinetics and safety of flumatinib mesylate in healthy subjects [19].

This study aimed to determine the effect of a high-fat, high-calorie diet on the pharmacokinetics of flumatinib and to evaluate the safety of oral administration of flumatinib $400 \mathrm{mg}$ in healthy subjects.

\section{Methods}

\section{Subjects}

Healthy Chinese subjects were screened for eligibility about 1 week before drug administration. Eligibility criteria included healthy Chinese adults, aged $18-45$ years, body mass index (BMI) of $19-24 \mathrm{~kg} / \mathrm{m}^{2}$, and a minimum weight of $50 \mathrm{~kg}$. The subjects had no history of cardiovascular, endocrine, metabolic, neurological, gastrointestinal, hepatic, pulmonary, infectious, immunological, or psychiatric diseases. We excluded subjects with a history of alcohol abuse, cigarette or drug dependence, or under concomitant treatments defined as using any drug that inhibits/induces hepatic metabolizing enzymes, within 30 days, or having undergone a surgery in the last 4 weeks. In addition, female subjects who were pregnant, planning on conceiving, using oral contraception, or in the menstrual cycle were excluded from this study.

The study was approved by the Medical Ethics Committee of the Third Xiangya Hospital of Central South University (an independent data safety monitoring committee, certificated by the Association for the Accreditation of Human Research Protection Program). All participants provided written informed consent prior to any studyrelated procedure.

\section{Study design}

This study was a single-center, randomized, open-label, two-period, crossover design to evaluate the effects of a high-fat diet on the pharmacokinetics of flumatinib in healthy subjects.

The subjects were randomized $24 \mathrm{~h}$ in advance in one of the two following groups. Group A: at least $10 \mathrm{~h}$ after fasting, oral flumatinib administration of $400 \mathrm{mg}$ (2 tablets, day 1 , first dose); the washout period was 14 days, half an hour after high-fat diet (timed from the start of diet) oral flumatinib administration of $400 \mathrm{mg}$ ( 2 tablets, day 15 ,second dose). Subjects in group B followed the opposite administration sequence from those in group A. In groups $\mathrm{A}$ and $\mathrm{B}$, the high-fat diet contained $800 \sim 1000 \mathrm{Kcal}$ (about $50 \%$ from fat) (meal composition is detailed Table 1).

\section{Pharmacokinetic evaluations}

Blood samples for pharmacokinetic (PK) evaluation were collected at $0 \mathrm{~h}$ before the initiation of dosing (pre-dose), and at $0.5,1,1.5,2,2.5,3,4,5,6,8,10,12,24,48,72$, and $96 \mathrm{~h}$ after dosing. Blood samples were centrifuged at $2000 \mathrm{~g}$ for $10 \mathrm{~min}$ at $4{ }^{\circ} \mathrm{C}$. Centrifugation was completed within $60 \mathrm{~min}$ after sample collection. The plasma was stored at $-70{ }^{\circ} \mathrm{C}$ for further analysis. Plasma concentrations of flumatinib and its main metabolites (M1 and M3) were determined using liquid chromatography-mass spectrometry (LC-MS/MS) [20]. 
Table 1 High-fat diet details*

\begin{tabular}{lccccccc}
\hline Nutrients & $\begin{array}{l}\text { Chinese oil } \\
\text { sticks }(100 \mathrm{~g})\end{array}$ & Egg $(100 \mathrm{~g})$ & Mixed oil $(30 \mathrm{~g})$ & $\begin{array}{l}\text { Terunsu milk } \\
(250 \mathrm{ml})\end{array}$ & Total $(\mathrm{g})$ & $\begin{array}{c}\text { Calories (KCal) } \\
\text { cercentage of } \\
\text { calories }(\%)\end{array}$ \\
\hline Protein $(\mathrm{g})$ & 6.90 & 13.3 & 0 & 9.00 & 29.2 & 117 & 11.9 \\
Carbohydrates $(\mathrm{g})$ & 50.1 & 2.80 & 0 & 12.5 & 65.4 & 261 & 26.5 \\
Fat (g) & 17.6 & 8.80 & 30.0 & 11.0 & 67.4 & 607 & 61.6 \\
Total & 74.6 & 24.9 & 30.0 & 32.5 & 162 & 985 & 100 \\
\hline
\end{tabular}

* $1 \mathrm{~g}$ protein was calculated by $4 \mathrm{kcal}$ calories, $1 \mathrm{~g}$ carbohydrate by $4 \mathrm{kcal}$ calories, and $\mathrm{lg}$ fat by $9 \mathrm{kcal}$ calories. The Chinese oil sticks were calculated according to the finished products, and the eggs and mixed oil were calculated by raw food weight. Only the breakfast on the first day of each cycle was different. Other meals were totally the same for all the subjects in this trial

\section{Safety evaluations}

All subjects who participated in the study were included in the safety analysis. Safety was evaluated by vital signs, physical examination, ECG, laboratory examination, adverse events (AEs), and combined medication. All adverse events that occurred during the trial were classified into mild, moderate and severe levels based on NCI CTCAE v4.03.

\section{Statistical analysis}

Phoenix WinNonlin Version 7.0 (Pharsight Corporation, Sunnyvale, CA, USA) software was used to calculate the pharmacokinetic parameters $\left(T_{\max }, C_{\max }, \mathrm{AUC}_{0-\mathrm{t}}\right.$, AUC $\left.0-\infty, t_{1 / 2}, \mathrm{~V} / \mathrm{F}, \mathrm{CL} / \mathrm{F}\right)$ of flumatinib and its main metabolites using a non-compartmental method (NCA module). Linear Up Log Down trapezoidal method was used for AUC calculation. The BE module of WinNonLin was used to analyze $\mathrm{AUC}_{0-t}, \mathrm{AUC}_{0-\infty}$, and $C_{\max }$ of flumatinib in fed and fasting states after logarithmic conversion. The treatment group (fasting, high-fat diet), the treatment sequence (A, B), and treatment phase were fixed effects in the model, and the subjects nested in the sequence were random effects. The adjusted mean difference (fasting/high-fat diet) and its $90 \%$ confidence interval estimated by the model, were taken as the negative number to obtain the corresponding PK parameter geometric mean ratio (postprandial/fasting), to estimate its $90 \%$ confidence interval, and to evaluate the effect of a high-fat diet on the pharmacokinetics of flumatinib.

\section{Results}

\section{Subjects}

This study was conducted between May 8, 2017 and June 10, 2017. Thirty-six eligible patients were invited to participate in the study; a total of 12 patients agreed to be enrolled and were randomly assigned to group A or group B ( $n=6$ each). One subject in group B withdrew due to adverse events before the second period (Fig. 1). Half of the subjects were male and half were female. Age, height, weight, and BMI of the subjects were $23.5 \pm 4.72$ years, $165.0 \pm 7.20 \mathrm{~cm}$, $59.2 \pm 5.10 \mathrm{~kg}$, and $21.8 \pm 1.92 \mathrm{~kg} / \mathrm{m}^{2}$, respectively. The demographic and baseline characteristics of all subjects are presented in Table 2. Twelve subjects were involved in pharmacokinetics evaluations of high-fat diet and safety analysis, 11 subjects were included pharmacokinetics evaluations of fasting and the food effect on flumatinib pharmacokinetics.

\section{Pharmacokinetic evaluations}

The mean plasma concentration versus time profiles of flumatinib, M1 and M3 in healthy Chinese subjects receiving a single oral dose of flumatinib mesylate tablet $(400 \mathrm{mg}$ ) are shown in Fig. 2. The $C_{\max }, \mathrm{AUC}_{0-\mathrm{t}}, \mathrm{AUC}_{0-\infty}$, and the secondary pharmacokinetic endpoints $\left(T_{\max }, T_{1 / 2}, \mathrm{~V} / \mathrm{F}, \mathrm{CL} / \mathrm{F}\right.$ and MRT) of flumatinib, M1 and M3 are shown in Table 3. Mean ( \pm standard deviation) $C_{\text {max }}, \mathrm{AUC}_{0-\mathrm{t}}, \mathrm{AUC}_{\mathbf{0}-\infty}$ of flumatinib in plasma after a high-fat diet $(132 \pm 54.5 \mathrm{ng} / \mathrm{ml}$; $1260 \pm 582 \mathrm{ng} \mathrm{h} / \mathrm{ml} ; 1277 \pm 586 \mathrm{ng} \mathrm{h} / \mathrm{ml}$, respectively) were higher than on fasting $(50.7 \pm 32.5 \mathrm{ng} / \mathrm{ml} ; 832 \pm 566 \mathrm{ng} \mathrm{h} /$ $\mathrm{ml} ; 847 \pm 572 \mathrm{ng} \cdot \mathrm{h} / \mathrm{ml}$, respectively). M1 exposure was also increased in presence of a high-fat meal, $\mathrm{C}_{\max }, \mathrm{AUC}_{0-\mathrm{t}}$ and $\mathrm{AUC}_{0-\infty}$ in plasma after high-fat diet $(54.7 \pm 25.5 \mathrm{ng} \mathrm{h} /$ $\mathrm{ml} ; 368 \pm 177 \mathrm{ng} \mathrm{h} / \mathrm{ml} ; 390 \pm 191 \mathrm{ng} \mathrm{h} / \mathrm{ml}$, respectively) were higher than that after fasting $(27.2 \pm 7.14 \mathrm{ng} / \mathrm{ml}$ : $231 \pm 101 \mathrm{ng} / \mathrm{ml} ; 243 \pm 108 \mathrm{ng} \mathrm{h} / \mathrm{ml}$, respectively). CL/F, $\mathrm{V} / \mathrm{F}$, and MRT in plasma after high-fat diet $(661 \pm 380 \mathrm{~L} / \mathrm{h}$; $11700 \pm 5130 \mathrm{~L} ; 19.2 \pm 3.37 \mathrm{~h}$, respectively) were lower than that after fasting $(399 \pm 229 \mathrm{~L} / \mathrm{h} ; 8470 \mathrm{v} \pm 4130 \mathrm{~L}, 17.2 \pm 3.66$ $h$, respectively).

\section{Effect of high-fat diet on the pharmacokinetics}

The least-square geometric mean (LSGM) ratio of flumatinib, M1, M3 and their 90\% confidence interval (CI) after high-fat diet/fasting are shown in Table 4 . The Cmax of flumatinib in plasma after a high-fat diet had nearly tripled over that in the fasted state, and the Cmax of M1 increased 1.9-fold. The $\mathrm{AUC}_{0-\mathrm{t}}$ and $\mathrm{AUC}_{0-\infty}$ of flumatinib and $\mathrm{M} 1$ 


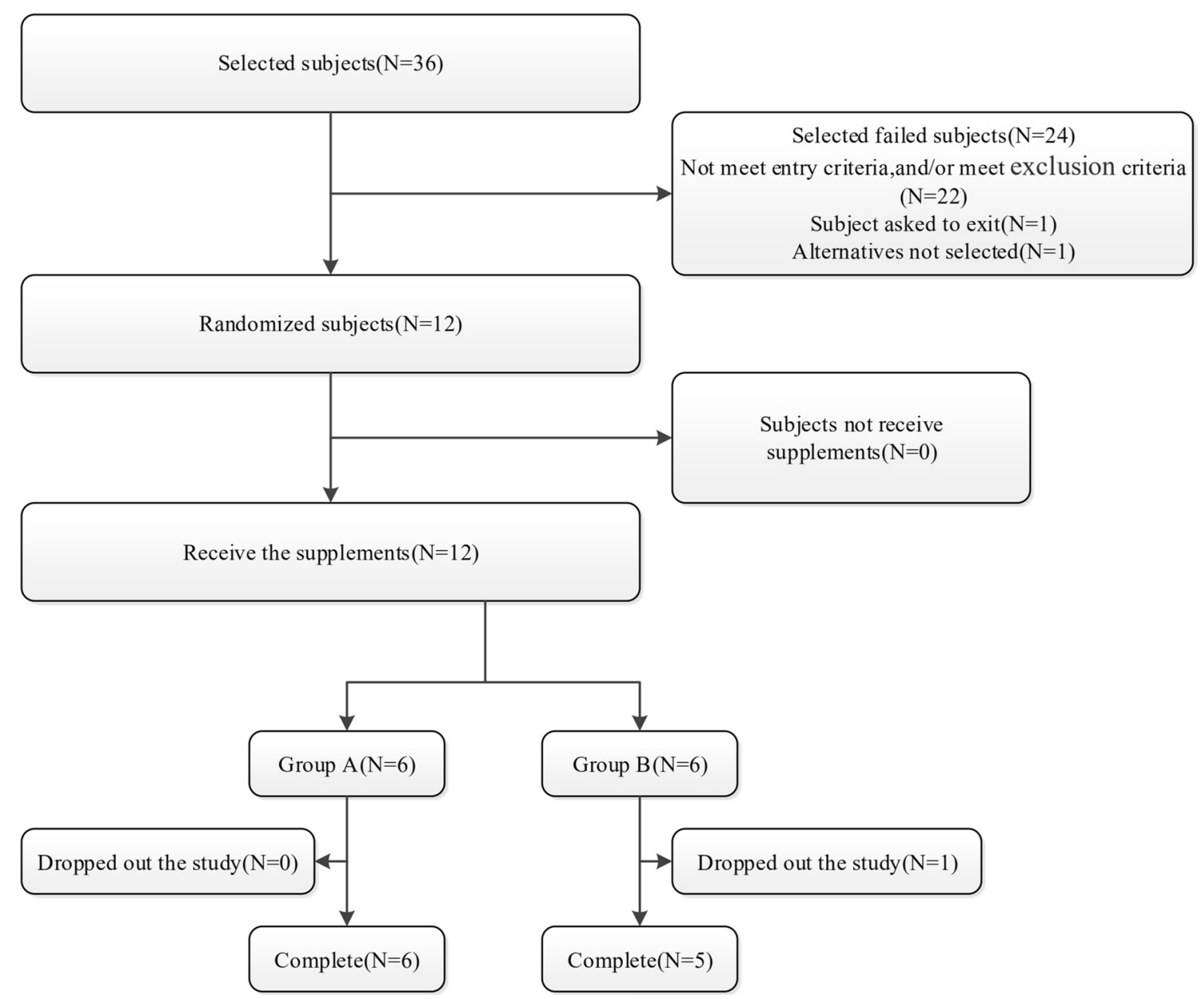

Fig. 1 Consort diagram detailing the total number of subjects recruited, withdrawn, and analyzed

Table 2 Demographic Information and Baseline Information of Subjects in Groups

\begin{tabular}{lllll}
\hline Variables & Statistics & Group A & Group B & Total \\
\hline $\begin{array}{l}\text { Total number } \\
\text { Sex (\%) }\end{array}$ & 6 & 6 & 12 \\
$\quad$ Male & & $3(50 \%)$ & $3(50 \%)$ & $6(50 \%)$ \\
Female & & $3(50 \%)$ & $3(50 \%)$ & $6(50 \%)$ \\
Age, years & Mean (SD) & $24.3 \pm 6.12$ & $22.7 \pm 3.14$ & $23.5 \pm 4.72$ \\
Height, cm & Mean (SD) & $165 \pm 6.22$ & $166 \pm 8.64$ & $165 \pm 7.20$ \\
Weight, kg & Mean (SD) & $60.0 \pm 3.77$ & $58.4 \pm 6.43$ & $59.2 \pm 5.10$ \\
BMI, kg/m ${ }^{2}$ & Mean (SD) & $22.3 \pm 2.05$ & $21.3 \pm 1.82$ & $21.8 \pm 1.92$ \\
\hline
\end{tabular}

Data are the mean $\pm \mathrm{SD}$, except sex (male/female), which is in \%

$B M I$ body mass index, $S D$ standard deviation

increased 1.6-fold. Except for the 90\% CI of M3 $\mathrm{AUC}_{0-\infty}$ which was within $80.00-125.00 \%$, the other parameters of flumatinib and metabolites M1 and M3 had 90\% CI outside $80.00-125.00 \%$. This indicated that a high-fat diet had a significant effect on pharmacokinetic of flumatinib, M1, and

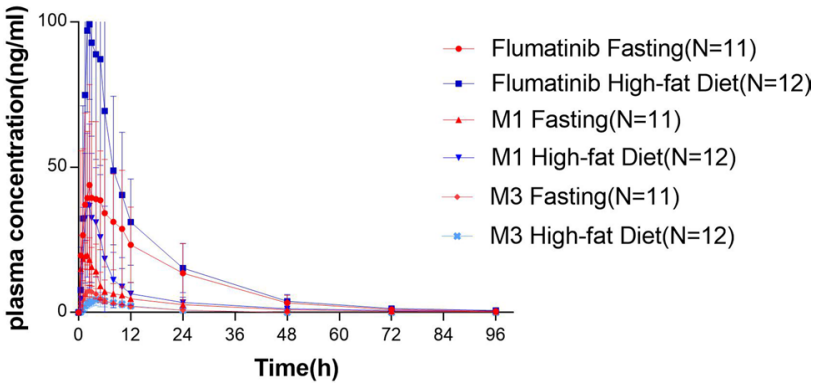

Fig. 2 Mean plasma concentration of flumatinib, M1, and M3 in healthy Chinese subjects receiving a single oral $400 \mathrm{mg}$ dose of flumatinib mesylate tablet

M3. And a high-fat diet can increase the peak concentration and systemic exposure of flumatinib and M1.

\section{Safety evaluations}

Safety evaluations were performed in all subjects $(n=12)$. In the fasting group, there were nine cases of 
Table 3 Pharmacokinetics Parameters of Fasting and High-fat Diet

\begin{tabular}{|c|c|c|c|c|c|c|}
\hline \multirow[t]{2}{*}{ Parameters } & \multicolumn{2}{|l|}{ Flumatinib } & \multicolumn{2}{|l|}{ M1 } & \multicolumn{2}{|l|}{ M3 } \\
\hline & Fasting $(N=11)$ & $\begin{array}{l}\text { High-fat diet } \\
(N=12)\end{array}$ & Fasting $(N=11)$ & $\begin{array}{l}\text { High-fat diet } \\
(N=12)\end{array}$ & Fasting $(N=11)$ & High-fat diet $(N=12)$ \\
\hline $\begin{array}{l}T_{\max }(\mathrm{h}) \\
\text { median(range) }\end{array}$ & $2.50(1.50-5.00)$ & $3.00(1.50-5.02)$ & $2.00(0.50-4.00)$ & $2.25(1.50-5.02)$ & $2.50(1.50-4.00)$ & $4.00(2.00-10.00)$ \\
\hline$C_{\max }(\mathrm{ng} / \mathrm{mL})$ & $50.7 \pm 32.5$ & $132 \pm 54.5$ & $27.2 \pm 7.14$ & $54.7 \pm 25.5$ & $7.95 \pm 2.07$ & $5.17 \pm 2.21$ \\
\hline $\mathrm{AUC}_{0-\mathrm{t}}(\mathrm{ng} \cdot \mathrm{h} / \mathrm{mL})$ & $832 \pm 566$ & $1260 \pm 582$ & $231 \pm 101$ & $368 \pm 176.6$ & $68.6 \pm 20.4$ & $56.6 \pm 21.9$ \\
\hline $\operatorname{AUC}_{0-\infty}(\mathrm{ng} \cdot \mathrm{h} / \mathrm{mL})$ & $847 \pm 572$ & $1277 \pm 586$ & $243 \pm 108$ & $390 \pm 191$ & $74.1 \pm 19.5$ & $66.1 \pm 25.5$ \\
\hline$t_{1 / 2}(\mathrm{~h})$ & $13.3 \pm 2.52$ & $15.5 \pm 4.67$ & $22.8 \pm 6.96$ & $24.4 \pm 5.80$ & $8.34 \pm 1.91$ & $8.52 \pm 2.40$ \\
\hline $\mathrm{CL} / \mathrm{F}(\mathrm{L} / \mathrm{h})$ & $661 \pm 380$ & $399 \pm 229$ & 1 & / & / & / \\
\hline $\mathrm{V} / \mathrm{F}(\mathrm{L})$ & $11,700 \pm 5130$ & $8470 \pm 4130$ & / & I & I & I \\
\hline MRT (h) & $19.2 \pm 3.37$ & $17.2 \pm 3.66$ & $24.3 \pm 4.37$ & $23.5 \pm 4.20$ & $11.5 \pm 2.52$ & $14.0 \pm 3.69$ \\
\hline
\end{tabular}

All data are given as the mean \pm standard deviation

$A U C_{0-t}$ area under the concentration-time curve from zero to the final measurable concentration, $A U C_{0-\infty}$ area under the concentration-time curve from time zero to infinity, $C_{\max }$ maximum concentration, $t_{1 / 2}$ elimination half-life, $M R T$ mean residence time

Table 4 Effect of high-fat diet on the pharmacokinetics of flumatinib, M1, and M3

\begin{tabular}{|c|c|c|c|c|c|c|c|c|c|}
\hline \multirow{2}{*}{$\begin{array}{l}\text { Pharma- } \\
\text { cokinetics } \\
\text { parameters }\end{array}$} & \multicolumn{3}{|c|}{ Flumatinib } & \multicolumn{3}{|l|}{ M1 } & \multicolumn{3}{|l|}{ M3 } \\
\hline & $\begin{array}{l}\text { Fasting } \\
(N=11)\end{array}$ & $\begin{array}{l}\text { High-fat diet } \\
(N=11)\end{array}$ & $\begin{array}{l}\text { LSGM ratio } \\
\text { high-fat diet/ } \\
\text { fasting (\%) } \\
(90 \% \mathrm{CI})\end{array}$ & $\begin{array}{l}\text { Fasting } \\
(N=11)\end{array}$ & $\begin{array}{l}\text { High- } \\
\text { fat diet } \\
(N=11)\end{array}$ & $\begin{array}{l}\text { LSGM ratio } \\
\text { high-fat diet/ } \\
\text { fasting (\%) } \\
(90 \% \mathrm{CI})\end{array}$ & $\begin{array}{l}\text { Fasting } \\
(N=11)\end{array}$ & $\begin{array}{l}\text { High- } \\
\text { fat diet } \\
(N=11)\end{array}$ & $\begin{array}{l}\text { LSGM ratio } \\
\text { high-fat diet/ } \\
\text { fasting }(\%) \\
(90 \% \mathrm{CI})\end{array}$ \\
\hline$C_{\max }(\mathrm{ng} / \mathrm{mL})$ & 43.7 & 123 & $282(226,351)$ & 26.3 & 49.6 & $189(145,245)$ & 7.69 & 4.88 & $\begin{array}{l}63.5(54.0, \\
74.6)\end{array}$ \\
\hline $\begin{array}{l}\mathrm{AUC}_{0-\mathrm{t}} \\
(\mathrm{ng} * \mathrm{~h} / \mathrm{mL})\end{array}$ & 696 & 1170 & $167(144,195)$ & 212 & 347 & $164(149,180)$ & 65.5 & 55.9 & $\begin{array}{l}85.2(74.7, \\
97.2)\end{array}$ \\
\hline $\begin{array}{l}\mathrm{AUC}_{0-\infty} \\
(\mathrm{ng} * \mathrm{~h} / \mathrm{mL})\end{array}$ & 710 & 1180 & $167(143,194)$ & 223 & 367 & $164(150,180)$ & 68.7 & 66.5 & $\begin{array}{l}96.7 \text { (86.6, } \\
108)\end{array}$ \\
\hline
\end{tabular}

$A U C_{0-t}$ area under the concentration-time curve from zero to the final measurable concentration, $A U C_{0-\infty}$ area under the concentration-time curve from time zero to infinity, $\mathrm{C}_{\max }$ maximum concentration

treatment-emergent adverse event (TEAE) (81.8\%) and eight $(72.7 \%)$ were related to the study drug. (Table 5). In the high-fat diet group, there were ten cases of TEAE (83.3\%) and seven $(58.3 \%)$ were related to the study drug. Except for one case of moderate acute gastroenteritis (withdrawal), the other TEAEs were mild. Acute gastroenteritis was completely relieved after treatments, including anti-infection, spasmolysis, antiemesis and acid suppression. Other mild adverse events disappeared without any treatment. The TEAE related to the drug included mild gastrointestinal symptoms (abdominal pain, diarrhea, and abdominal distension) and mild laboratory abnormalities (alanine aminotransferase, blood magnesium, and uric acid slightly increase).

\section{Discussion}

The results of the Phase Ia clinical trial showed that there were significant differences in $\mathrm{AUC}_{0-\mathrm{t}}$ and $\mathrm{C}_{\max }$ of flumatinib and M1 between fasting and high-fat diet $(p<0.05)$, implying the oral absorption of flumatinib could be promoted by postprandial administration. These are similar to the results of our study in healthy people. This is consistent with a report on a similar drug (ivosidenib), in which a 98\% increase in Cmax was observed in healthy subjects who were given the drug after a high-fat diet, as compared to the fasting [21]. The increase in bioavailability of lapatinib after low-fat and high-fat diet were $167 \%$ and $325 \%$, respectively [22]. The reasons for our results are as follows, First, a highfat diet increases the secretion of bile acid (BA), especially secondary BA, such as deoxycholic acid and lithocholic acid, which slows gastric emptying and weakens intestinal peristalsis, resulting in prolonged retention time of flumatinib in the gastrointestinal tract, thereby increasing absorption [23]. Second, flumatinib is a lipophilic drug, thus, a high-fat diet can increase the solubility of flumatinib, thereby promoting drug absorption and increasing its (relative) bioavailability 


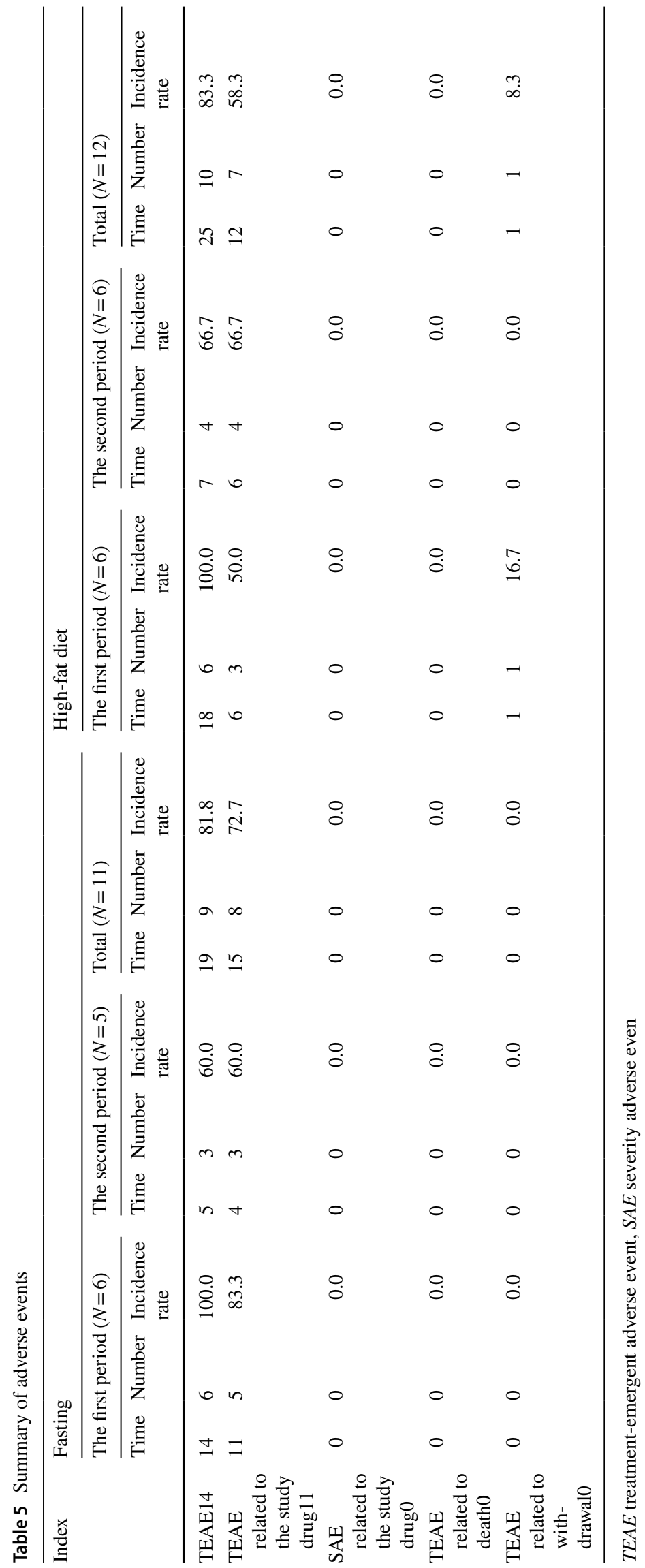




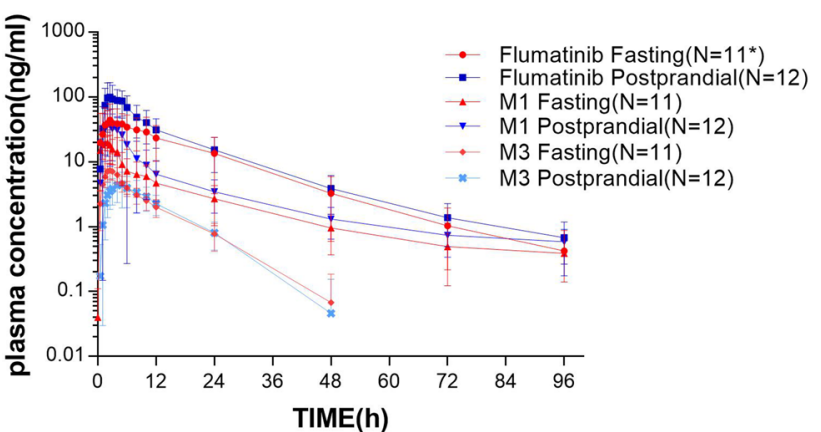

Fig. 3 Semi-logarithmic plots of mean plasma concentration of flumatinib, M1 and M3 in chinese healthy subjects receiving a single oral $400 \mathrm{mg}$ dose of flumatinib mesylate tablet

[24]. The $C_{\max }$ and $\mathrm{AUC}_{0-\mathrm{t}}$ of $\mathrm{M} 3$ after a high-fat diet was decerased compared with that of fasting. This may be due to poor detection sensitivity as the M3 proportion is small. Alternatively, postprandial administration had less effect on the parent drug to M3 metabolic pathway. CL/F and V/F of flumatinib are huge because flumatinib has a low bioavailability. First, based on the BCS(Biopharmaceutics Classification System) Guidance of the year 2000, flumatinib is classified as BCS Class III. Second, a large amount of unmetabolized parent drug was detected in the feces after oral administration, which may be related to oral malabsorption caused by the low-permeability of flumatinib. Third, the bioavailability of flumatinib increased after high-fat meal, indicating that high-fat diet improved the low- permeability of flumatinib and improved the low-bioavailability of flumatinib, so the $\mathrm{CL} / \mathrm{F}$ and $\mathrm{V} / \mathrm{F}$ of postprandial administration decreased correspondingly (Fig. 3).

The incidence of TEAE was similar between the two conditions, while the incidence of TEAE related to the study drug after high-fat diet was better than that of fasting. However, it is uncertain whether the safety of the drug after a high-fat diet is better than that after fasting due to the small sample size. TEAEs including mild gastrointestinal symptoms and mild laboratory abnormalities are similar to most of the adverse reactions in oncology. For example, the FDA labels warnings of the potential for liver toxicity and rare cases of fatal liver failure [25].

The combination of a high-fat diet with flumatinib increased the bioavailability of flumatinib and M1. So taking it with food (which may increase its bioavailability) may have clinical implications, such as toxic reactions and increased accumulation. In this study, there was no significant increase in adverse reactions after a high-fat diet as compared with fasting. Combined with the clinical data of Phase II and III, the exposure and bioavailability of flumatinib after a high-fat diet was increased, so postprandial administration may have potential risks. The exposure and bioavailability of nilotinib, which is a BCR-ABL tyrosinase inhibitor, increased significantly after administration with food compared with fasting. In healthy subjects, $C_{\max }$ and AUC were reported to be $112 \%$ and $82 \%$ higher when taken with food than fasting [26]. Therefore, the marketing instructions for nilotinib indicate that it should be taken on an empty stomach. Therefore, in terms of the selection of the drug administration recommended in the later stage of clinical practice, flumatinib may only be taken on an empty stomach without food.

\section{Conclusion}

Oral administration of flumatinib at a single dose of $400 \mathrm{mg}$ was safe and well tolerated in healthy subjects on fasting or a high-fat diet. However, considering the significant increase (67\%) in the exposure to flumatinib when taken with food, flumatinib may be recommended to be taken in the fasted state.

Acknowledgements This study was supported by National Major New Drug Creation Project of China (No. 2020ZX09201-010), International Science and Technology Cooperation Program of China (No. 2014DFA30900) and National Natural Science Foundation of China (81673519).

Author contributions All authors contributed to the study conception and design. Jie Huang, Qing-nan He designed and supervised the research. Material preparation, data collection and analysis were performed by YK, H-1S, G-pY, QP, X-yY, LY, SY, H-tW, CG performed research. The first draft of the manuscript was written by $Y K$ and all authors commented on previous versions of the manuscript. YK, JH and Q-nH reviewed and modified the manuscript. All authors read and approved the final manuscript.

\section{Compliance with ethical standards}

Conflict of interest There are no competing interests to declare.

Open Access This article is licensed under a Creative Commons Attribution 4.0 International License, which permits use, sharing, adaptation, distribution and reproduction in any medium or format, as long as you give appropriate credit to the original author(s) and the source, provide a link to the Creative Commons licence, and indicate if changes were made. The images or other third party material in this article are included in the article's Creative Commons licence, unless indicated otherwise in a credit line to the material. If material is not included in the article's Creative Commons licence and your intended use is not permitted by statutory regulation or exceeds the permitted use, you will need to obtain permission directly from the copyright holder. To view a copy of this licence, visit http://creativecommons.org/licenses/by/4.0/.

\section{References}

1. Deininger MW, Goldman JM, Melo JV (2000) The molecular biology of chronic myeloid leukemia. Blood 96(10):3343-3356 
2. Nowell PC, Hungerford DA (1960) Chromosome studies on normal and leukemic human leukocytes. J Natl Cancer Inst 25:85-109

3. Rowley JD (1973) Letter: A new consistent chromosomal abnormality in chronic myelogenous leukaemia identified by quinacrine fluorescence and Giemsa staining. Nature 243(5405):290-293. https://doi.org/10.1038/243290a0

4. Goldman JM, Melo JV (2003) Chronic myeloid leukemiaadvances in biology and new approaches to treatment. N Engl J Med 349(15):1451-1464. https://doi.org/10.1056/NEJMra020777

5. Druker BJ (2008) Translation of the Philadelphia chromosome into therapy for CML. Blood 112(13):4808-4817. https://doi. org/10.1182/blood-2008-07-077958

6. Sawyers CL (2010) Even better kinase inhibitors for chronic myeloid leukemia. N Engl J Med 362(24):2314-2315. https:// doi.org/10.1056/NEJMe1004430

7. Kabarowski JH, Witte ON (2000) Consequences of BCR-ABL expression within the hematopoietic stem cell in chronic myeloid leukemia. Stem Cells 18(6):399-408. https://doi.org/10.1002/ stem.180399

8. Odwyer M (2002) Multifaceted approach to the treatment of bcrabl-positive leukemias. Oncologist 7(Suppl 1):30-38. https://doi. org/10.1634/theoncologist.7-suppl_1-30

9. Okuda K, Weisberg E, Gilliland DG, Griffin JD (2001) ARG tyrosine kinase activity is inhibited by STI571. Blood 97(8):2440 2448. https://doi.org/10.1182/blood.v97.8.2440

10. Zhao J, Quan H, Xu Y, Kong X, Jin L, Lou L (2014) Flumatinib, a selective inhibitor of BCR-ABL/PDGFR/KIT, effectively overcomes drug resistance of certain KIT mutants. Cancer SCI 105(1):117-125. https://doi.org/10.1111/cas.12320

11. Luo H, Quan H, Xie C, Xu Y, Fu L, Lou L (2010) HH-GV-678, a novel selective inhibitor of Bcr-Abl, outperforms imatinib and effectively overrides imatinib resistance. Leukemia 24(10):18071809. https://doi.org/10.1038/leu.2010.169

12. Gong A, Chen X, Deng P, Zhong D (2010) Metabolism of flumatinib, a novel antineoplastic tyrosine kinase inhibitor, in chronic myelogenous leukemia patients. Drug Metab Dispos 38(8):1328-1340. https://doi.org/10.1124/dmd.110.032326

13. Todd M, Meyers ML, Charnas R, Acharya M, Molina A (2012) Fast and flawed or scientifically sound: the argument for administering oral oncology drugs during fasting. J Clin Oncol 30(8):888889. https://doi.org/10.1200/JCO.2011.39.7851

14. Food and Drug Administration FDA (2018) Expansion cohorts: use in firstin-human clinical trials to expedite development of oncology drugs and biologics guidance for industry 2018

15. Kishino E, Ogata R, Saitoh W, Koike Y, Ohta Y, Kanomata N, Kurebayashi J (2019) Anti-cell growth and anti-cancer stem cell activity of the CDK4/6 inhibitor palbociclib in breast cancer cells. Breast Cancer-Tokyo. https://doi.org/10.1007/s12282-019-01035 $-5$

16. Khalaf DJ, Annala M, Taavitsainen S, Finch DL, Oja C, Vergidis J, Zulfiqar M, Sunderland K, Azad AA, Kollmannsberger CK, Eigl BJ, Noonan K, Wadhwa D, Attwell A, Keith B, Ellard SL, Le L, Gleave ME, Wyatt AW, Chi KN (2019) Optimal sequencing of enzalutamide and abiraterone acetate plus prednisone in metastatic castration-resistant prostate cancer: a multicentre, randomised, open-label, phase 2, crossover trial. Lancet Oncol 20(12):1730-1739. https://doi.org/10.1016/S1470-2045(19)30688 $-6$

17. Ramanathan S, Jin F, Sharma S, Kearney BP (2016) Clinical pharmacokinetic and pharmacodynamic profile of idelalisib. Clin Pharmacokinet 55(1):33-45. https://doi.org/10.1007/s4026 2-015-0304-0

18. de Jong J, Sukbuntherng J, Skee D, Murphy J, O’Brien S, Byrd JC, James D, Hellemans P, Loury DJ, Jiao J, Chauhan V, Mannaert E (2015) The effect of food on the pharmacokinetics of oral ibrutinib in healthy participants and patients with chronic lymphocytic leukemia. Cancer Chemother Pharmacol 75(5):907-916. https:// doi.org/10.1007/s00280-015-2708-9

19. Food and Drug Administration FDA (2018) Clinical pharmacology 1: phase 1 studies and early drug development

20. Yang Y, Liu K, Zhong D, Chen X (2012) Simultaneous determination of flumatinib and its two major metabolites in plasma of chronic myelogenous leukemia patients by liquid chromatography-tandem mass spectrometry. J Chromatogr B Analyt Technol Biomed Life Sci 895-896:25-30. https://doi.org/10.1016/j.jchro mb.2012.03.008

21. Chi KN, Spratlin J, Kollmannsberger C, North S, Pankras C, Gonzalez M, Bernard A, Stieltjes H, Peng L, Jiao J, Acharya M, Kheoh T, Griffin TW, Yu MK, Chien C, Tran NP (2015) Food effects on abiraterone pharmacokinetics in healthy subjects and patients with metastatic castration-resistant prostate cancer. J Clin Pharmacol 55(12):1406-1414. https://doi.org/10.1002/jcph.564

22. Messori A (2007) Effect of food on lapatinib pharmacokinetics. J Clin Oncol 25(33):5332-5335. https://doi.org/10.1200/ JCO.2007.13.9345

23. Mithani SD, Bakatselou V, TenHoor CN, Dressman JB (1996) Estimation of the increase in solubility of drugs as a function of bile salt concentration. Pharm Res 13(1):163-167. https://doi. org/10.1023/a:1016062224568

24. Singh BN (1999) (1999) Effects of food on clinical pharmacokinetics. Clin Pharmacokinet 37(3):213-255

25. Cohen MH, Williams G, Johnson JR, Duan J, Gobburu J, Rahman A, Benson K, Leighton J, Kim SK, Wood R, Rothmann M, Chen G, Staten AM, Pazdur R (2002) Approval summary for imatinib mesylate capsules in the treatment of chronic myelogenous leukemia. Clin Cancer Res 8(5):935-942

26. Li CH, Sherer EA, Lewis LD, Bies RR (2015) Clinical trial simulation to evaluate population pharmacokinetics and food effect: capturing abiraterone and nilotinib exposures. J Clin Pharmacol 55(5):556-562. https://doi.org/10.1002/jcph.449

Publisher's Note Springer Nature remains neutral with regard to jurisdictional claims in published maps and institutional affiliations. 